\title{
FRONTERAS DIBUJADAS: LA REPRESENTACIÓN DE LAS FRONTERAS EN LA FORMACIÓN DOCENTE PERMANENTE
}

\author{
JORGELINA TALLEI \\ Professora da UNILA \\ jorgelina.tallei@unila.edu.br \\ LAURA JANAINA DIAS AMATO \\ Professora da UNILA \\ laura.amato@unila.edu.br \\ JOSÉ LINDOMAR ALBUQUERQUE \\ Professora da UNIFESP \\ jose.lindomar@unifesp.br
}

La región transfronteriza y trinacional entre Foz de Iguaçu (Brasil), Puerto Iguazú (Argentina) y Ciudad del Este (Paraguay) es un lugar donde se vive, transita y se imagina la frontera. Desde los espacios de convivencia fronteriza podemos pensar los límites de nuestras tradiciones de pensamientos marcadas por los encuadramientos nacionales, así también podemos imaginar y actuar en las posibilidades políticas y pedagógicas de construir puentes políticos, culturales y simbólicos entre los y las habitantes de la región.

\section{Por un encuentro entre educación, arte y frontera}

Este capítulo busca comprender una experiencia de acción formativa del programa de extensión universitaria Pedagogía intercultural/de frontera de la Universidad Federal de Integración Latinoamericana (UNILA) en colaboración con docentes de la Universidad del Oeste de Paraná (UNIOESTE) y del Instituto Federal Tecnológico campus Foz de Iguazú (IFPR), especialmente la producción de dibujos y/o diseños sobre la frontera producidos por docentes de la red municipal de Foz de Iguaçu (Brasil) que participaron de este programa entre 2016 y 2019. El programa nació con la perspectiva de reflexionar sobre el contexto socio-histórico y geográfico en el cual docentes de la red básica de Foz do Iguazú actúan, pensando en políticas públicas y acciones concretas que contemplen los sujetos escolares en toda su complejidad. Es organizado por los/as investigadores del grupo de investigación Linguagem, Politica e Cidadania de la UNILA en colaboración con la Secretaria de Educación Municipal de Foz de 
Iguazú (SMED). Fue en el ámbito de estas acciones formativas que fueron propuestas diversas acciones visando comprender la realidad de la región entre los tres países desde la visión de las docentes en formación permanente. Entre esas acciones, una de la más significativa fue la producción de dibujos a partir del sentir y del vivir en la frontera.

Estas producciones son, en las acciones formativas, pensadas como un recurso pedagógico de aprendizaje en el momento de su elaboración y también como una representación simbólica de la realidad vivenciada. Podríamos decir que es un acto de producción del conocimiento que posibilita pensar diferentes dimensiones de comprensión de la realidad y visiones relacionadas a los deseos y sueños de integración e inclusión. Las docentes que participaron del programa de formación permanente son personas con diferentes experiencias e imaginarios de vida en la región de frontera, algunas nacieron y crecieron en la ciudad de Foz de Iguazú y otras migraron de otros lugares y se tornaron profesoras en el municipio ${ }^{1}$.

De este modo, el objetivo del capítulo es comprender algunos significados de los dibujos a partir de su contexto de producción, es decir, del proceso político de pensar y actuar por una pedagogía en/de fronteras. Para eso es importante entender cuál es la perspectiva de los estudios fronterizos que utilizamos en el análisis y que ideas de frontera se trabajaron durante uno de los talleres de la formación permanente. Por último, nos dedicaremos a reflexionar sobre las, posibles, nociones de frontera presentes en los dibujos elaborados por las docentes municipales.

\section{La frontera y los sujetos (trans) fronterizos}

El concepto de frontera evoca diversos significados y diferentes metodologías de estudios. Escogimos aproximarnos de la frontera como zona de contacto con el objetivo de comprender algunas dimensiones de los fenómenos lingüísticos, culturales y simbólicos presentes en los dibujos. Dialogamos, así, con la propuesta de Mary Pratt cuando esta afirma que:

1 Llamaremos en el femenino dado que fueron mayoría en el taller. 
Tal abordagem consideraria o modo como as diferenças e as hierarquias são produzidas no contato e pelo contato dessas linhas umas com as outras. [...] Tal 'perspectiva do contato' assumiria a heterogeneidade de um grupo social e poria em primeiro plano a relacionalidade do sentido. (Pratt, 1999, p. 12).

La perspectiva del contacto busca pensar la frontera como realidad relacional, desigual y ambivalente, constituida por relaciones de encuentro y desencuentro, conflicto e integración, identidad y alteridad en un espacio de copresencia. En un sentido metafórico, simboliza puentes y barreras con la otredad en los espacios sociales de contacto. La idea de zona de contacto, elaborada por la autora para pensar procesos y situaciones coloniales, puede aproximarse a la noción de fronteridad en las zonas de convivencia fronteriza. Para Norma Prieto:

Las fronteridades trabajan como condiciones de sentido, es decir, la frontera, como demarcación geopolítica, genera una multiplicidad de condiciones legales y socioculturales (fronteridades); éstas, a su vez, marcan y moldean la forma en la que vivimos y experimentamos la frontera. Estas experiencias - individuales y sociales- al mismo tiempo marcan, moldean y atribuyen sentido a la experiencia. Desde ahí se construye entonces la representación y el imaginario social. (Prieto, 2014, p. 100).

Los sujetos que viven en las zonas o regiones de contacto entre países son generalmente llamados de fronterizos o transfronterizos. El término fronterizo puede acentuar la idea de singularidad y liminalidad de las áreas de frontera, diferenciándose del nacional de otras regiones de los respectivos países, justamente porque recibe influencias culturales de las zonas cercanas del o de los países aledaños. También, en diversas situaciones de frontera, el habitante fronterizo puede, incluso, obtener un documento de ciudadano fronterizo, posibilitando el tránsito y el acceso a servicios o trabajos en las ciudades cercanas del país vecino. El concepto de 
convivencia fronteriza hace hincapié en esta dimensión de la frontera como realidad singular definida por la cercanía, contacto armonioso y conflictivo e intercambios variados, sin perder de vista las divisiones administrativas, rituales burocráticos, los controles y los contornos que hacen parte del cotidiano de los habitantes de distintas zonas fronterizas.

Sin embargo, la idea de fronterizo no enfatiza la dimensión del cruce cotidiano entre los límites nacionales. De este modo, el término transfronterizo visa justamente pensar distintas dimensiones de las travesías entre límites nacionales y las propias configuraciones y conexiones de estas regiones pobladas entre países, haciendo hincapié en los cruces, los intercambios y relaciones sociales entre un lado y otro de la frontera. Partimos entonces de entender el concepto transfronterizo desde Rodríguez Ortiz:

Desde mi perspectiva, lo transfronterizo se debe entender como el intercambio de registros psicosociales y simbólicos entre sujetos disímiles en un espacio indefinido pero delimitado (limes) por una frontera geopolítica. Al ser los transfronterizos sujetos de derecho no es posible pensar en fronteras porosas, como aluden algunos teóricos liberales, pero es debido a la existencia de estas barreras jurídico-administrativas que tanto el fenómeno migratorio como las zonas de convivencia fronteriza le dan forma a las prácticas transfronterizas. (Ortiz, 2014, p. 58).

En este sentido, podemos pensar la propia área de confluencia entre países como una región transfronteriza, una vez que hay variados circuitos, flujos e intercambios de personas, mercancías, símbolos, imágenes, dineros, etc. entre estos territorios vecinos y que ocurren debido a la propia existencia de los límites políticos de los Estados nacionales y sus padrones de desarrollo económico y social desiguales.

Preferimos comprender estas ciudades formando simultáneamente espacios urbanos transfronterizos y trinacionales, una vez que la dimensión nacional de cada ciudad de frontera es también 
reafirmada cotidianamente por medio de las diferencias administrativas en las distintas áreas (política, documentos de ciudadanía, salud, educación, etc.), por los idiomas nacionales, por las identificaciones de las personas y sus simbologías nacionales (Albuquerque, 2020). A su vez, es importante destacar que ni todos los que viven en las ciudades de frontera cruzan cotidianamente los límites entre países. Hay sujetos fronterizos que nunca o raramente cruzan para el "otro lado de la frontera" por distintas razones, desde barreras físicas y falta de documentación hasta cuestiones de desconocimiento, prejuicio y discriminación con el país vecino y sus ciudadanos.

De este modo, estamos pensando el término transfronterizo a partir de las movilidades cotidianas entre límites nacionales relacionadas a las redes familiares, circuitos comerciales, formas de trabajo, sociabilidades y ocios, así como los desplazamientos por cuestiones de salud y educación. En el ámbito de la educación en la frontera los sujetos transfronterizos son sobre todo aquellos docentes, funcionarios de las escuelas y estudiantes que viven en un país y trabajan o estudian en la nación vecina, así como aquellos marcados por las experiencias familiares de tránsito y migración entre los países aledaños. El programa Pedagogía intercultural/ de frontera enfoca su mirada hacia estos sujetos escolares transfronterizos, especialmente los estudiantes de las escuelas municipales de Foz de Iguazú, en la red de enseñanza primaria (de primer a quinto año) como también en la formación docente permanente y los desafíos de formarse en un contexto multilingüe e intercultural.

\section{Pedagogía intercultural/de frontera}

Rescatamos la historia, brevemente, del programa a fin de contextualizar la producción de dibujos y su posterior análisis. El programa Pedagogía Intercultural/de Frontera nace a partir de la discontinuidad del Programa Escuelas Interculturales de Frontera $(\mathrm{PEIF})^{2}$. El trabajo de formación docente permanente realizado

2 El Programa de Escuelas Interculturales de Frontera (PEIF) está vinculado a una política educativa del gobierno del estado, por medio de la Secretaria Educativa del Mercosur (SEM). En la UNILA, el PEIF se desarrolló entre los años 2011 y 2015. Para Sturza, "el objetivo principal del PEIF es desarrollar un modelo de escuela que considere la realidad lingüística, cultural, social y educativo de las zonas fronterizas" (Sturza, 2014, p. 4). 
por medio del PEIF en el año 2015, en la UNILA, posibilitó que las docentes de la red municipal que participaron de las acciones de formación expusieran diversas vivencias en la escuela con la llegada de estudiantes de diversas nacionalidades. Una de las vivencias presentadas hace referencia a la falta de programas de formación docente permanente direccionados a pensar la realidad transfronteriza o a la falta de continuidad de políticas públicas que visibilicen la cotidianidad de frontera en materia educativa. Por otro lado, en la gestión del PEIF en la UNILA se realizaron dos seminarios con la presencia de personal vinculado a la SMED, así como de los municipios de los países vecinos, tal fue el caso de Argentina. Estos seminarios fueron fundamentales para abordar los desafíos de planificar una educación de frontera. Las docentes apuntaban, fundamentalmente, la necesidad de priorizar la formación docente a partir de realidades fronterizas y considerando prácticas investigativas con trabajos vinculados entre universidad y a las escuelas, un asesoramiento en las escuelas para tratar los temas que envuelven a la frontera y el personal docente en las escuelas, entre otros.

Así, era fundamental dirigir el interés en programas de formación docente permanente que posibiliten la reflexión de prácticas interculturales y plurilingües desde las características del contexto trinacional. Fue a partir de estas inquietudes que inició el programa de formación. En un primer momento, el nombre del programa - pedagogía intercultural - se enfocó en el concepto de interculturalidad a partir de la perspectiva crítica de Catherine Walsh. La autora parte de tres conceptos de análisis hasta llegar a definir lo que denomina como interculturalidad crítica. La primera línea de análisis es la que define como una interculturalidad relacional y es la que hace referencia a su sentido más básico, esto es: el intercambio entre culturas. Según Walsh, esta definición enmascara el concepto de colonialismo implícito en ella. La segunda perspectiva es la interculturalidad funcional, que en sus palabras:

[...] se enraíza en el reconocimiento de la diversidad y diferencia culturales, con metas a la inclusión de la misma al interior de la estructura social establecida. Desde esta perspectiva - que busca promover el diálo- 
go, la convivencia y la tolerancia -, la interculturalidad es "funcional" al sistema existente, no toca las causas de la asimetría y desigualdad sociales y culturales. (Walsh, 2010, p.79).

La última perspectiva presentada por la autora corresponde a la interculturalidad crítica. Esta concepción es entendida como una reflexión sobre la complejidad de pensar desde la diversidad a partir de un análisis de los procesos dinámicos que se generan en el contacto entre las varias lenguas y culturas desde el punto de vista social, cultural, económico y político. Esto provoca lazos geolingüísticos y reflexiones sobre la identidad desde una visión que engloba cuestiones de inclusión, sobre el sujeto, el lenguaje y la cultura.

A partir de entender, entonces, la formación docente desde una perspectiva intercultural como la dinámica de procesos relacionados de lenguas, culturas, dimos destaque a la denominación pedagogía intercultural. Y a partir del año 2018 el programa pasa a llamarse Pedagogía de Frontera entendiendo el concepto desde la perspectiva de Giroux:

[..] importantes elementos de una pedagogía de frontera, conformada por el criticismo postmoderno, toman una dirección en la cual las narrativas maestras, basadas en concepciones específicas de clase, patriarcales y de la raza blanca, pueden ser críticamente desafiadas y efectivamente desterritorializadas. $\mathrm{O}$ sea, al ofrecer un lenguaje teórico para establecer nuevas fronteras con respecto al conocimiento, la mayoría de las veces asociado con los márgenes de la cultura dominante, los discursos postmodernos abren la posibilidad de incorporar al currículo una noción de pedagogía de frontera en la cual las prácticas culturales y sociales ya no necesitan ser ubicadas o referidas sólo en base a los modelos dominantes de la cultura occidental. (Giroux, 1992, p. 35).

La reflexión del autor nos permite comprender que en las diversas acciones formativas es posible cuestionar los saberes hegemóni- 
cos de la escuela e incluir otras formas de saber desde nuestra condición de estar en la frontera entre naciones, clases sociales, grupos étnicos, géneros, conocimientos formales e informales, entre otros. Esto redefine el propio concepto de interculturalidad ahora pensado desde el lugar de frontera con la finalidad de que la escuela se transforme en un espacio de gestión e inclusión de las alteridades.

El programa tiene como principio una metodología de acción participativa desde la mirada del sociólogo colombiano Fals Borda. $\mathrm{O}$ sea, un método activo que requiere la participación constante y prolongada de grupos de personas implicadas en la transformación del territorio a través de acciones específicas. Fals Borda afirma que, cuando el grupo se empodera en sus saberes en busca de la transformación social y educativa, podemos hablar del ser sentipensante que es, según el autor:

El problema de la relación entre el pensar y el ser - la sensación y lo físico - se resuelve por la observación de lo material que es externo a nosotros e independiente de nuestra conciencia; y lo material incluye no sólo lo constatable de la naturaleza sino también las condiciones fundamentales, primarias, de la existencia humana. (Borda, 2009, p. 256).

Desde 2016 hasta 2019 participaron del programa más de 161 docentes de toda la red básica del municipio. En el año 2016 el programa tuvo como objetivo conocer las percepciones de las docentes de la red municipal sobre el trabajo en aula con estudiantes transfronterizos/as. En este sentido fueron trabajadas temáticas sobre diversidad, interculturalidad y contexto trinacional. Importante destacar que en el municipio nunca se había ofertado un curso, proyecto o programa de formación permanente considerando esta temática. Por tanto, el primer año fue de reconocimiento y escucha. Las actividades formativas se concentraron en el análisis de documentos marco del PEIF a fin de analizar las concepciones de interculturalidad y lengua que eran propuestas en el documento. 
En el año 2017, el objetivo del programa se centró en la oferta de acciones formativas que discutieron la región y a su vez se trabajó en colaboración para la organización de una propuesta de formación docente permanente de acuerdo con las inquietudes y demandas docentes presentadas. Podemos resumir las principales acciones en: realización junto a la SMED de un análisis sociolingüístico de los estudiantes determinando quiénes son los sujetos escolares; levantamiento en todas las escuelas de la red municipal sobre la realidad de los estudiantes transfronterizos; a partir de los datos levantados diálogo con las docentes de la red y la SMED para propuestas de un plan de formación docente permanente. En el año 2018, el objetivo fue la elaboración de materiales didácticos aplicados a la realidad transfronteriza y acciones para la formación docente permanente en el área de lengua castellana por medio de la sensibilización en las escuelas y comunidad local. Ya en el año de 2019 las acciones, además de la formación permanente con diversos cursos, se llevó a cabo la realización de un proyecto piloto de un curso de español e inglés en dos escuelas del municipio y la elaboración de un documento fundacional para el municipio, como el protocolo de acogida para estudiantes migrantes en la red básica de la ciudad, finalizado en julio de $2020^{3}$.

Antes de abordar los dibujos, cabe decir que la acción que describimos a continuación forma parte de una serie de reflexiones que se iniciaron en 2016 con 25 docentes de diferentes escuelas de la red de enseñanza básica del municipio. En el año de 2017, trabajamos con parte de las docentes (15 en total) que ya habían realizado las acciones de formación en el año anterior. Para este año se propuso trabajar a partir de dos ejes de acciones formativas: la primera de ellas, reflexionar sobre temáticas para pensar la frontera y el lugar del sujeto transfronterizo; la segunda acción fue la realización de diferentes proyectos de investigación implicando a las escuelas y a la comunidad. Las propuestas de formación y estrategias se iniciaron con diversos talleres que debatían tres temáticas: frontera, interculturalidad y lenguas.

3 El documento está disponible en: https://dspace.unila.edu.br/handle/123456789/5879. Fecha de consulta: 11 de agosto de 2020. 


\section{Representaciones visuales de la frontera en el proceso de formación docente}

El trabajo con recursos visuales es un desafío ya que hay una tendencia epistemológica en valorizar el trabajo escrito. Sin embargo, es importante resaltar las características de un mundo multisemiótico y multimodal, o sea, textos escritos, orales, audiovisuales, magnéticos, todos son plausible de análisis e interpretaciones. Por lo que la elección de trabajar con imágenes se basa en una perspectiva multi interpretativa, en la cual las emociones están presentes y lo simbólico de lo "no dicho" atraviesan cada trazo y cada color posibilitando representar aquello que no es posible traducir en palabras. Según Theron et al.:

O desenho, em particular, pelo seu traçado reflexivo, estimula o distanciamento, a reflexão, a construção cognitiva e a interação, permitindo aos participantes, a par de uma encenação diferente da que é permitida pela palavra, centrar-se nos meandros das suas relações com as línguas e envolver-se, de forma mais criativa, nas suas aprendizagens. (Theron et al., 2011 ${ }^{4}$ apud Melo-Pfeifer; Simões, 2017, p. 13).

Las autoras destacan la complejidad de trabajar con el concepto de imagen. Moore (2001) enfatiza que la imagen que los actores sociales tienen de una lengua y una cultura influencia los procedimientos y estrategias desarrolladas para lidiar con otra lengua y cultura. Debemos considerar, además, que el concepto de imagen tiene como base diferentes ciencias, como la Psicología Social, la Antropología y la Sociología y por ser plausible de varias interpretaciones es también transdisciplinar. Las imágenes por sus características propias también manifiestan y explican los comportamientos del individuo y traducen la sociedad en la cual conviven. De este modo, Melo-Pfeifer y Simões afirman que:

4 Theron, L.; Mitchell, C.; Smith, A.; Stuart, J. (Eds). Picturing research: drawings as visual methodology. Rotterdam: Sense Publishers, 2011. 
[...] as imagens são o produto de uma construção coletiva e social, que se adaptam a várias situações, são processos históricos, socioidentitários, cognitivos e discursivos próprios de cada indivíduo ou grupo, fazem parte da língua para que possam organizar e categorizar o mundo, de forma a serem utilizadas através do discurso, uma vez que influenciam o modo como os sujeitos interagem com a realidade. (Melo-Pfeifer; Simões, 2017, p. 59).

Melo-Pfeifer y Ferreira (2017, p. 132) traen importantes características sobre el análisis de dibujos y de imágenes, en las cuales debemos observar el potencial narrativo que "materializa categorías como tiempo, espacio, acción y personajes", por lo tanto también la noción de escala es importante en lo que refiere a la representación. Además, las autoras resaltan el potencial autoexplicativo del dibujo y de la imagen, pudiendo o no haber verbalización de/sobre el dibujo y la imagen, siendo esta explicación también plausible de subjetividades y matices.

\section{Las fronteras diseñadas de los ríos y los puentes}

Los dibujos de las docentes sobre la región transfronteriza pueden ser comprendidos como formas de mirar, sentir y pensar la frontera en un contexto espacial y temporal específico. Son elaboraciones simbólicas que expresan percepciones, significados, lenguajes, signos, artes y deseos delante de un espacio social singular. Intentamos realizar, así, un ejercicio reflexivo a partir de una selección de algunos dibujos, de los comentarios de las docentes sobre los significados atribuidos a los dibujos y pensar algunas dimensiones de posibles lecturas de estas representaciones visuales. Como ya afirmamos, todas las acciones del programa Pedagogía de Frontera se dividieron en tres líneas de discusión: frontera, interculturalidad y lenguas, incluso los talleres de dibujos. Al terminar de realizar las producciones visuales, cada representación de cada grupo de docentes era colocada en la pizarra. Esto permitía que todas las docentes expresen y reflexionen sobre las imágenes. Los debates a partir de las imágenes serán considerados e interpretados en nues- 
tro análisis. Elegimos algunos de las tantas producciones realizadas de dibujos para pensar algunas representaciones sobre la frontera.

Iniciamos este apartado contextualizando la actividad realizada en uno de los talleres del programa de formación permanente y en el cual participaron diversas docentes, de enseñanza infantil y primaria de la red municipal de enseñanza de la ciudad de Foz de Iguazú. El taller fue realizado en el año de 2017 y tuvo una duración de cinco horas, por la tarde, impartido por la docente formadora de la UNILA en colaboración con la docente formadora de la UNIOESTE y del IFPR campus Foz de Iguazú. El eje del taller giró alrededor del concepto de frontera. La propuesta era reflexionar en colaboración con las docentes participantes sobre conceptos claves que nos permiten pensar el contexto y el lugar que ocupamos como docentes en la región trinacional.

Para realizar la actividad las docentes fueron divididas en cinco grupos. Como consigna debían dibujar representaciones de frontera partir de la definición dada en la pizarra: "En la frontera los procesos de cambio imaginario aceleran una construcción ficcional del otro" (Aguilera Olmos, 2013, p. 25). Al principio, se sorprendieron con la instrucción y cuestionaron casi de manera unánime: ¿pero qué frontera? La docente formadora entonces resaltó la importancia de pensar la frontera desde experiencias de la vida cotidiana.

Cuando observamos los diferentes dibujos destacamos que ocuparon un lugar de gran interés en el debate los símbolos del puente y el río. De hecho, ambos - el puente y el río - tienen un valor simbólico relevante en distintos contextos nacionales e internacionales. De una manera general, el puente puede simbolizar la voluntad humana de unión entre las orillas de un río visualizadas como separadas. Es un objeto estético para fines prácticos de circulación de personas y bienes y fuente de conexión entre la naturaleza y la cultura (Simmel, 2001). El río, a su vez, es un paisaje natural que simboliza tanto la separación de sus orillas y puede servir como delimitación y demarcación de las llamadas "fronteras naturales", como el movimiento de unión de los flujos de sus aguas en cuyo lecho atraviesan los transportes fluviales 
que ligan sus márgenes a lo largo de la historia. Los ríos internacionales - Iguazú y Paraná - y los puentes de Amistad y Tancredo Neves adquieren muchos significados en la configuración territorial de Foz de Iguazú, como narrativa de la frontera en su dimensión geopolítica marcando la presencia del estado nacional en sus diferentes significaciones, así como de las dinámicas sociales y económicas entre las ciudades y países fronterizos, son emblemas de separación como de integración.

Los dibujos que seleccionamos en este capítulo indican distintas perspectivas sobre el puente y el río. En el dibujo 1 observamos trazos en blanco y negro, con rasgos minimalistas y asimétricos y realizados desde una perspectiva área (figura 1). Los elementos centrales son las circulaciones de personas y autos, el puente y el río. Hay un destaque especial al tamaño de dos personas, una en cada lado de la frontera y con una seta de sentido doble.

Figura 1 - Dibujo del puente, el río y circulación

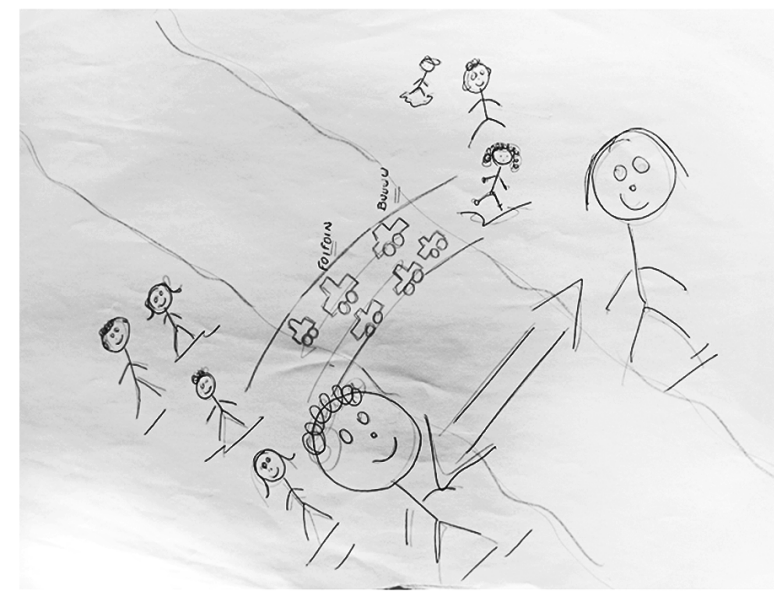

Fuente: acervo del proyecto, 2017.

En el dibujo 2 pensado desde la perspectiva del río, visualizamos varios colores, con trazos bien definidos (figura 2). Los elementos centrales del escenario son el pescador en su barco, el puente con el sol y al fondo la pequeña isla en el centro del río desde la mirada de quien cruza el puente. Al detenernos en la imagen podemos distinguir la arquitectura del Puente Internacional de la 
Amistad-Brasil y Paraguay. Podemos pensar, además, algunos contrastes significativos con relación al dibujo anterior, especialmente pensando la centralidad del pescador en su barco en primer plano, la mirada del puente desde abajo, sin tránsitos de autos o personas, y una isla paradisíaca al fondo, sin demarcaciones claras de una frontera internacional y sin direcciones demarcadas.

Figura 2 - Dibujo de pescador, puente e isla

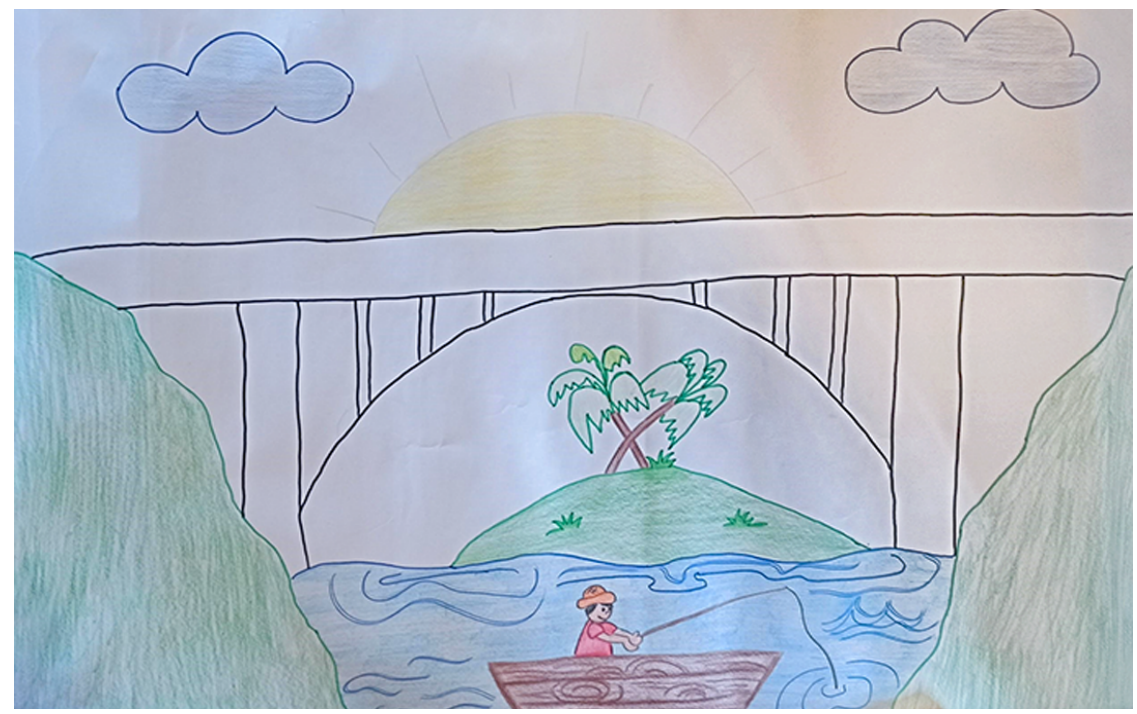

Fuente: acervo del proyecto, 2017.

Para las docentes que participaron de la actividad, la frontera está asociada directamente al puente: "quando pensamos em fronteira sempre lembramos da ponte. A ponte acaba representando aquilo que nos une de um país para outro. Euma ligação com nossos irmãos”. Sobre el dibujo 1, enfatizan que "a fila de carros parece o Paraguai, sempre filas lotadas de carros e com muitas pessoas que cruzam a ponte. A fronteira parece uma via de duplo sentido construindo juntos". Sobre la figura 2, las docentes destacan que el imagen de la isla "sempre nos lembra o Paraguai, ela sempre está quando cruzamos a ponte e sempre parece muito importante" o aún "a isla é identificação, ela se ve na ponte. E o rio de cor azul, parece o mar". En relación al pescador, subrayan que "o pescador está quando vemos a fronteira, sempre está no rio, parece como o xiru”. 
Los dibujos seleccionados y los comentarios de las docentes nos ayudan a problematizar algunas dimensiones de estas representaciones visuales. En primer lugar, la visibilidad de la dimensión monumental de la frontera desde la centralidad del Puente de Amistad en los dibujos y los relatos de las docentes está asociada a las nociones de unión, integración y hermandad, lo que difiere bastante de las regiones de frontera cuyos monumentos son los muros, cercas o aduanas con significativos controles de los tránsitos. En segundo lugar, la relación entre experiencia, memoria y representación (individual y colectiva) de la frontera, es decir, la frontera no es simplemente una realidad objetiva, sino principalmente una realidad subjetiva e intersubjetiva marcada por la relacionalidad de sentido, los significados de los tránsitos comerciales, las experiencias cotidianas de la travesía del puente, las prácticas fronterizas y transfronterizas que moldean nuestras percepciones de los símbolos materiales de la frontera. En tercer lugar, las miradas trasversales que podemos formular desde el diseño del pescador. El pescador podría ser pensado relacionado a las prácticas económicas tradicionales y en una otra temporalidad con relación al ritmo de los tránsitos en el puente. Sin embargo, los comentarios de las docentes brasileñas relacionan al sujeto pescador al "xirú" (término ambivalente que probablemente derive de la expresión guaraní che iru (mi amigo/compañero), pero también es usado por los brasileños de modo peyorativo para referirse a los paraguayos. Es decir, el pescador que podría significar el desdibujar del límite nacional en el río, puede también representar una frontera marcada por el estigma hacia el otro.

Por otro lado, observamos que, en varias imágenes, la representación del río y del puente estaban vinculadas a la frontera Brasil - Paraguay, siendo la zona fronteriza entre Argentina - Brasil poco mencionada o representada. Ese hecho tal vez se justifique dada la centralidad de las dinámicas transfronterizas (comerciales, familiares, trabajo, salud, educación, entre otras) entre Foz do Iguazú (Brasil) y Ciudad del Este (Paraguay) al comparar con las relaciones cotidianas entre Foz do Iguazú y Puerto Iguazú (Argentina). Las propias docentes mantienen más contactos con la ciudad paraguaya, pues van a Ciudad del Este por compras domésticas y escolares más baratas, parientes y amigos que trabajan o viven del "otro lado de la frontera" y algunas tienen alumnos brasiguayos en 
sus aulas, y en varias ocasiones llegaron a llamar la ciudad vecina como si fuera un "barrio de Foz" 5 . De esta forma el cruce constante por el Puente de Amistad y la mirada panorámica sobre el Río Paraná, muchas veces a pie debido a los embotellamientos cotidianos en el puente, producen sentimientos, imágenes y narrativas variadas sobre estos símbolos de la frontera Brasil-Paraguay. La frontera Argentina - Brasil, con dinámicas transfronterizas menos intensas y con controles aduaneros más rígidos, son representadas especialmente por las simbologías de las banderas nacionales y por el punto turístico del hito de las tres fronteras.

Aunque los dos dibujos anteriores no representen claramente los límites nacionales en los puentes y ríos, otros diseños de la misma actividad refuerzan la dimensión geopolítica de la frontera, con banderas nacionales de los países vecinos al lado de los ríos. En el dibujo 3 observamos dos pequeños trechos de tamaño simétrico del río internacional dibujados de forma discontinua, marcando la división entre los tres países (figura 3). Parece ser referente al Río Paraná (río que forma el límite entre Brasil y Paraguay y en seguida entre Paraguay y Argentina).

En la representación visual no se identifica claramente el río entre Brasil y Argentina (Río Iguazú), aunque tal vez las autoras del dibujo buscaron representar los dos ríos internacionales. Vale una referencia especial a las dimensiones de las tres banderas nacionales ubicadas en lados opuestos de los ríos, simbolizando los respectivos territorios nacionales. Podemos también imaginar que se trata de un dibujo construido desde la perspectiva geográfica del Brasil, por la posición que se encuentra la bandera de Brasil con relación a la bandera del Paraguay y Argentina.

En el dibujo 4 nos llaman la atención tres elementos centrales: el abismo entre dos montañas de tierras con colores distintos (amarrillo y verde), el puente sobre el abismo uniendo los territorios a su vez separados y con personas yendo en la dirección del puente y las banderas nacionales de los países aledaños

5 Los alumnos brasiguayos son conocidos como aquellos descendientes de inmigrantes brasileños que viven en Paraguay o retornaron al Brasil, así como los hijos de padre o madre paraguaya con madre o padre brasileño y viven o vivieron período de la vida en el territorio paraguayo. 
en un mismo hito de frontera en el territorio de la izquierda, hito también pintado con colores referentes a las tres naciones vecinas. En este diseño el río no aparece y los hitos de la frontera no están separados en lados opuestos a la confluencia del Río Paraná y del Iguazú como lo es de hecho (figura 4).

Figura 3 - Ríos, banderas y fronteras nacionales
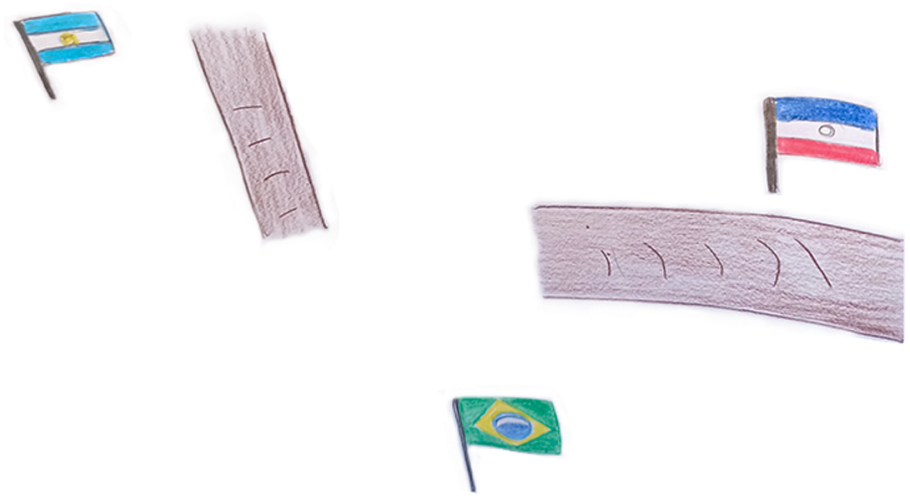

Fuente: acervo del proyecto, 2017.

Figura 4 - Fronteras como separación

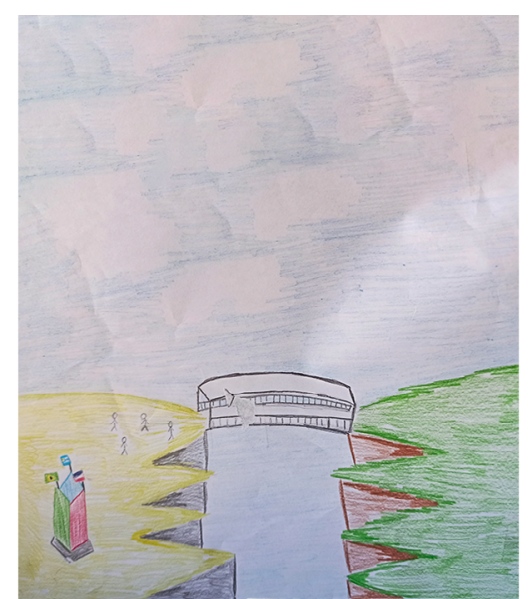

Fuente: acervo del proyecto, 2017.

Es posible ver que las docentes destacaron los colores de las banderas nacionales pintados en los propios puentes. En sus 
relatos sobre la interpretación de estos dibujos, dicen: "sempre visualizamos as bandeiras quando cruzamos a ponte" $y$ "as bandeiras são representadas nas pontes". Con relación al diseño 3, ellas relatan que "as fronteiras nos separam". Referente al dibujo 4, consideran que «é difícil conhecer do lado argentino, tem a aduana que fica solicitando muitas coisas, parece o abismo do desenho", "as cores das bandeiras está ruim nas pontes, nem dá para identificar que país está pintado" y "seria legal ter um marco com todas as bandeiras como está desenhado".

Las banderas nacionales son símbolos de fuerte reproductibilidad en nuestro medio. En las zonas de fronteras internacionales, las banderas adquieren significado especial, una vez que representan a la vez el fin y el comienzo del territorio nacional marcado de manera visible en el paisaje para aquellos que salen o llegan a estos territorios representados simbólicamente como discontinuos, aunque el paisaje natural sea el mismo. Además, las banderas en las fronteras sirven como símbolo de contraste de las identidades nacionales en los respectivos territorios de la nación. Como recuerdan las docentes al mirar a las banderas en el dibujo 3, "las fronteras nos separan". Las banderas nacionales son, por tanto, mecanismos simbólicos de producción y reproducción cotidiana de las comunidades imaginadas de las naciones (Anderson, 2008) y sus usos pueden ser simultáneamente geopolíticos, económicos y simbólicos. Cuando observamos las banderas en los hitos de las tres fronteras y los puentes pintados hasta la mitad con los colores de la bandera de cada país vecino, notamos que pueden representar los límites políticos, fuente de atracción turística, símbolo de la identidad nacional, entre otros significados posibles. Cuando observamos el dibujo 4 y los comentarios de las docentes que participaron de la actividad, vemos que hay a la vez una dimensión de denuncia de la separación y otra de deseo de integración entre los territorios. La denuncia puede referirse a la imagen del territorio separado por el abismo y el comentario de una docente sobre las dificultades con la aduana. Tanto la simbología de la nación como los mecanismos de control del Estado argentino son vistos como dispositivos de separación. Sin embargo, la imagen del puente sin colores nacionales visibles y del hito de frontera con las tres ban- 
deras juntas y de un mismo lado puede representar el deseo político de construir una imaginación transfronteriza futura más allá de la configuración del presente.

Al observar la simbología del color amarillo y verde de los dos territorios separados como referencias a dos colores de la bandera de Brasil, es posible todavía señalar que el abismo y la separación pueden estar presentes de manera más expresiva en un mismo territorio nacional que entre naciones vecinas. Esto es, en una ciudad fronteriza como Foz de Iguazú las barreras entre clases sociales, etnias, nacionalidades, religiones, pueden ser más significativas que aquellas entre habitantes de los países vecinos. Y en este sentido, una pedagogía intercultural/de frontera se propone construir puentes de conocimiento y de acción política tanto con las docentes y con los estudiantes transfronterizos que cruzan los puentes entre los países vecinos y enfrentan barreras en el cotidiano escolar, como también con los sujetos fronterizos que (tal vez) no atraviesan los puentes internacionales y viven en zonas de contacto marcados por diferencias y desigualdades en la ciudad de Foz de Iguazú y son atravesados por diversas fronteras.

\section{Posibles caminos para avanzar}

La propuesta de este artículo es despertar una reflexión a partir de algunos de los tantos dibujos de las docentes, como forma de pensar estrategias interculturales para contextos transfronterizos. Los talleres que trabajaron las representaciones posibilitaron a las docentes participantes expresarse de forma libre y espontánea, conectada a un saber íntimo y compartido. Las docentes colocaron en el papel lo que sienten y viven en su cotidiano de sujetas transfronterizas. Además, el análisis semiótico, subjetivo e individual se sumó a una interpretación colectiva de las imágenes, verbalizada con experiencias propias de cada una de las participantes. Los dibujos que rescatamos en el presente artículo expresan, de cierta forma, la materialidad del ser transfronterizo que se manifiesta entre el ir y venir entre puentes y ríos. A su vez, las diversas representaciones simbolizan una mezcla de lo fijo y lo rígido del concreto con la fluidez del agua. La metáfora de lo concreto del puente y del flujo del agua podemos relacionarlas con vivencias cotidianas en la región 
ya que al mismo tiempo que soy un sujeto (único), concreto; el agua me convierte en un ser permeable y mutable para actuar con el otro.

Los programas de formación docente permanente para las fronteras deben posibilitar una reflexión desde la condición de docentes transfronterizas en interrelación con los procesos históricos, sociales y culturales del territorio a partir del lugar afectivo que la frontera también ocupa. Las docentes a veces visualizan un lugar de cierta forma romántico de la frontera, aún muy conectado al estado nación. Es de igual importancia reflexionar sobre un lugar transcultural o si se prefiere el entre lugar, que posibilite el reconocimiento de la interculturalidad desde el lugar de frontera. En este sentido, un posible camino parta de las propias concepciones docentes cuando contemplan la posibilidad de nuevos sentidos a partir del contacto de las culturas, del diálogo y la solidaridad.

\section{Referencias}

AGUILERA OLMOS, Miguel (coord.). Antropología de las fronteras: alteridad, historia y memoria más allá de la línea. Tijuana: Ed. Digital, 2013. 375 p.

ALBUQUERQUE, José Lindomar. Espacios urbanos transfronterizos y trinacionales: aproximaciones sobre las triples fronteras entre Foz do Iguaçu (BR)/Ciudad del Este (PY)/ Puerto Iguazú (AR) y Tabatinga (BR)/Letícia (CO) / Santa Rosa (PER) In: Hernandez, Alberto (org.). Puentes que unen y muros que separan: fronterización, securitización y procesos de cambios en las fronteras de México y Brasil. Tijuana: El Colegio de la Frontera Norte, 2020.

ANDERSON, Benedict: Comunidades imaginadas: reflexões sobre a origem e difusão do nacionalismo. Tradução: Denise Bottman. São Paulo/Companhia das Letras, 2008. 336p

FALS BORDA, Orlando. Una sociología sentipensante para América Latina. Bogotá: Clacso/Siglo del Hombre Editores, 2009. 492 p.

GIROUX, Henry A. La pedagogía de frontera y la política del posmodernismo. Revista Intringulis, n. 6, p. 37-42, sep./dic. 1992.

MELO-PFEIFER, Silvia \& SIMÕES, Ana Raquel(ed.). Plurilinguismo vivido, plurilinguismo desenhado: estudos sobre a relação dos sujeitos com as línguas. 2017. E-Book. https://www.researchgate.net/ publication/321221118_Melo-Pfeifer_Simoes_2017_ed_Plurilinguis- 
mo_vivido_plurilinguismo_desenhado_estudos_sobre_a_relacao_ dos_sujeitos_com_as_linguas_E-Book. Acceso en enero de 2020. MELO-PFEIFER, Silvia, FERREIRA, Teresa. Diz-me lá o que é que tu desenhaste aqui!" - das narrativas visuais a uma intertextualidade multimodal? In: MELO-PFEIFER, Silvia; SIMÕES, Ana Raquel. (Eds.). Plurilinguismo vivido, plurilinguismo desenhado: estudos sobre a relação dos sujeitos com as línguas. 2017. E-Book. https:// www.researchgate.net/publication/321221118_Melo-Pfeifer_Simoes_2017_ed_Plurilinguismo_vivido_plurilinguismo_desenhado_estudos_sobre_a_relacao_dos_sujeitos_com_as_linguas_E-Book. Acesso em janeiro de 2020.

MOORE, Danièle. (Coord.). Les représentations des langues et de leur apprentissage. Références, modèles, données et méthodes. Paris: Didier, 2001.

ORTIZ RODRIQUEZ, Roxana. Epistemología de la frontera: modelos de sociedad y políticas públicas. Distrito Federal: EON, 2014. 103 p. PRATT, Mary. A crítica na zona de contato: nação e comunidade fora de foco. Revista Travessia, n. 38, 1999, p. 7-29. PRIETO, Norma Iglesias. Tijuana provocadora. Transculturalidad y processos creativos. In: Valenzuela Arce, José Manuel (Comp.). Transfronteras. Fronteras del mundo y procesos culturales. Tijuana: Colegio de la Frontera Norte, 2014, p. 97-127.

SIMMEL, Georg. Puente y puerta. In: El individuo y la libertad: ensayos de crítica de la cultura. Barcelona: Peninsula, 2001.

STURZA, Eliana. Das experiências e dos aprendizados no Programa Escolas Interculturais de Fronteiras. In: Salto para o Futuro Escolas Interculturais de Fronteira, Ano XXIV, Boletim 1, maio de 2014, p. 4-7.

WALSH, Catherine. Interculturalidad crítica y educación intercultural. In: VIAÑA, Jorge; TAPIA, Luis; WALSH, Catherine (Orgs.). Construyendo interculturalidad crítica. La Paz: Convenio Andrés Bello, 2010, p. 75-96. 